\title{
A Review of the literature on performance feedback and organizational response
}

\author{
Chen Can* \\ Nanjing University of Science and Technology,Nanjing, China \\ *Corresponding author: 744690253@qq.com
}

\begin{abstract}
Performance feedback is one of the core propositions of the theory of enterprise behavior, and it is the basic mechanism that affects the organizational response. It provides an important analytical perspective for the study of enterprises' strategic behaviors, such as innovation and change. However, performance feedback is very complex, the existing research literature has multiple theoretical directions, inconsistent empirical findings, and different measurement methods. To this end, this paper systematically reviewed the relevant literature.
\end{abstract}

Keywords: Performance feedback; Performance expectation; organization response.

\section{Introduction}

Performance feedback is one of the core propositions of the theory of enterprise behavior, and it is an important theoretical basis for understanding the behavior and decision-making mode, learning and adaptation, evolution and development of enterprises.

Organizational actions such as enterprise innovation, enterprise strategic change and enterprise foreign direct investment are considered as the response of the organization to performance feedback. However, the conclusions of different research topics are not consistent, and there are important influencing factors in the performance feedback mechanism: Greve (1998) believed that the gap between the actual performance and the expected level would improve the tolerance of enterprises and lead to more risk coping behaviors [1]. Chen et al. (2007) found that with the widening of performance expectation gap, the bankruptcy threat caused by extremely poor performance would make enterprises become conservative [2].

\section{Performance feedback and organizational response}

\subsection{The connotation of performance feedback}

Cyert and March (1963) believe that when a company encounters various problems in operation and management, the company manager will launch a problem search mechanism to find solutions [3]. Specifically, when the company's actual performance fails to reach the expected goal, in order to bridge the gap, the company's managers will constantly seek solutions according to the deviation between the actual performance and the expected performance during the decision-making process by adopting problem-seeking behavior.

Lant etc. (1992) [4] argue that, "expected performance" as a core problem in the process of searching for policymakers, its essence is "make the decision makers are satisfied with the minimum output", and the company of the gap between actual performance and expected performance is referred to as "performance gap", the performance gap, in turn, affect the decision-making behavior of policymakers is the process of the "expected performance feedback". Among them, the performance gap can be divided into two situations. One is that the actual performance fails to meet the expected performance, and the decision maker will consider the organization to be in a state of "loss", that is, the expected performance gap range. In the second case, the actual performance is higher than the expected performance. In this case, the decision maker will think that the organization is in the state of "benefit", that is, the expected performance surplus range. 


\subsection{The connotation of organizational response}

How does the organization respond to performance feedback? Scholars have carried out rich research from the perspectives of strategic organizational change and business. Li Can et al. (2019) systematically sorted out existing researches on organizational response behaviors caused by performance feedback and summarized the following eight common organizational response behaviors [5]. This is shown in Table 1.

Table.1. summarizes the types of response behavior

\begin{tabular}{|c|c|}
\hline Response behavior type & Main indicators \\
\hline Innovative search & R\&D investment 、 increase of new products \\
\hline Marketing research & Marketing research、Marketing adaptive search \\
\hline Strategic change & Strategic change index 、 Strategic convergence/divergence \\
\hline New Relationship Building & Build new partnerships \\
\hline Add/delete business units & $\begin{array}{c}\text { Merger and break-up of business units 、 Product additions and } \\
\text { deletions }\end{array}$ \\
\hline Capacity expansion & Resource acquisition, Growth in the value of productive assets \\
\hline $\begin{array}{c}\text { Violation and social } \\
\text { responsibility }\end{array}$ & Financial irregularities \\
\hline corporate political behavior & Political lobbying \\
\hline
\end{tabular}

Source: Excerpt from paper by Li Can et al

The above eight kinds of organizational response behaviors can also be divided into market response behaviors and non-market response behaviors. 1-6 belongs to market response behaviors, among which innovative search is the most studied and discussed by scholars. 7 and 8 are non-market response behaviors, but there are few relevant researches.

\section{The relationship between performance feedback and organizational response}

Among many academic theories that trace back to the formulation mechanism of organizational behavior, the theory of firm behavior asserts that expected performance feedback can influence the choice of firm behavior. On this basis, Barnard and Simon put forward the hypothesis of bounded rationality that there is no universally applicable fixed decision criteria as a reference in the decisionmaking customization process for relatively complex enterprise strategic behaviors, such as merger and acquisition, investment in innovation, research and development, transformation and upgrading etc. In addition, due to the limitation of decision-makers' personal cognitive ability, personal location difference, information processing ability and other characteristics, enterprise management is often unable to develop a "foolproof" solution.

Therefore, managers take the expected level of performance as the self-determined business goal, and take the gap between actual performance and business goal as the basis for the selection of strategic behavior. When the performance expectation surplus is in, it indicates that the organization is satisfied with the current operating state, and the enterprise has a weak motivation to make strategic adjustment and reform, and generally tends to maintain the current strategy. On the contrary, if the actual performance is not satisfied, that is, the actual performance is lower than the expected performance, the decision-maker will be more alert. In order to narrow the performance expectation gap and reverse the performance gap, the risk-taking level of the decision-maker will be improved, and the motivation for strategic reform will be enhanced. 


\section{Contingency factors affecting performance feedback mechanism}

\subsection{Corporate governance factors}

The decision of organizational adjustment and change depends on the strategic leader to a large extent, while the relevant factors of corporate governance will affect the attention, intention and decision reaching of the decision maker. Scholars began to pay attention to the moderating effect of corporate governance factors, such as CEO compensation and power, board of directors and founding executives, on the performance feedback mechanism.

\subsection{Organizational factors}

The existing literature on performance feedback and enterprise behavior theory has a rich discussion on the moderating factors at the organizational level, mainly focusing on the aspects of enterprise resources, corporate governance, organizational structure, multiple objectives, etc. Organizational scale can reverse management risk-taking, i.e. underperforming leads smaller firms to take less risk and larger firms to take more risk.

\subsection{Industry factors}

Some studies have explored the moderating factors at the industry level that influence the relationship between performance feedback and firm response, such as industry dynamic environment, industry research and development characteristics and environmental ambiguity. Industry dynamics will weaken the effect of negative performance feedback on corporate strategy to a certain extent and enhance the effect of positive performance feedback. Vague and indistinguishable industry or environmental information can weaken managers' perception that they have reached survival levels or threatened reference points even when the actual losses of business units are not large.

\subsection{Institutional or cultural factors}

More and more papers begin to focus on the contingent influence of institutional or cultural factors, and believe that managers' risk taking is limited by institutional factors. Especially in emerging markets such as China, the most significant environmental factor is institutional characteristics, which significantly affect the strategic choice of enterprises. In countries or regions dominated by collectivist culture, such as Japan, the performance feedback model would be affected by the interaction between society and culture.

\section{Conclusions and future research direction}

The research achievements of the Institute of Performance Feedback and Organizational Response are fruitful. However, due to the multiple theoretical orientation and the uneven and intersecting research findings, the accumulated literature is somewhat complex and has been stagnant [5]. This is mainly because the researchers rely on the conventional data methods, are limited by the rigid model in empirical analysis, and lack of motivation in theoretical innovation. There is more room for improvement in the research based on the Chinese context, and there is much to be done.

Currently, no research has linked performance feedback at the organizational level to performance evaluation at the individual level. One possible direction for future research is to link these two independent streams of research to perform a multi-level analysis. In addition, the existing research data and methods are relatively simple. Our future research could consider using different data sources from different countries and industries to enrich our understanding of how organizations respond to performance feedback.Future research can consider using different data collection methods, such as field studies and case studies, to better understand the performance feedback mechanism based on expectations. 


\section{References}

[1] Greve, H.R.. Performance, Aspirations, and Risky Organizational Change. Administrative Science Quarterly, 1998, 43(1):58-86.

[2] Chen,W.R., Miller,K.D.. Situational and Institutional Determinants of Firms R\&D Search Intensity. Strategic Management Journal, 2007, 28(4): 369-381.

[3] Cyertrm, M, March, J.G.. A behavioral theory of the firm[M].NJ:Englewood Cliffs, 1963.

[4] Lant, T.K.. Aspiration Level Adaptation: An Empirical Exploration [J]. Management Science, 1992,38(5).

[5] Li Can, LV Weixing, ZHOU Changhui. Performance feedback and organizational response: a literature review and prospects [J]. Foreign economics and management,2019,41(10):86-108. 